Document downloaded from:

http://hdl.handle.net/10251/79831

This paper must be cited as:

Rubio Michavila, C.; Candelas Valiente, P.; Belmar Ibáñez, F.; Gómez Lozano, V.; Uris Martínez, A. (2015). Subwavelength slit acoustic metamaterial barrier. Journal of Physics D: Applied Physics. 48(39):1-9. doi:10.1088/0022-3727/48/39/395501.

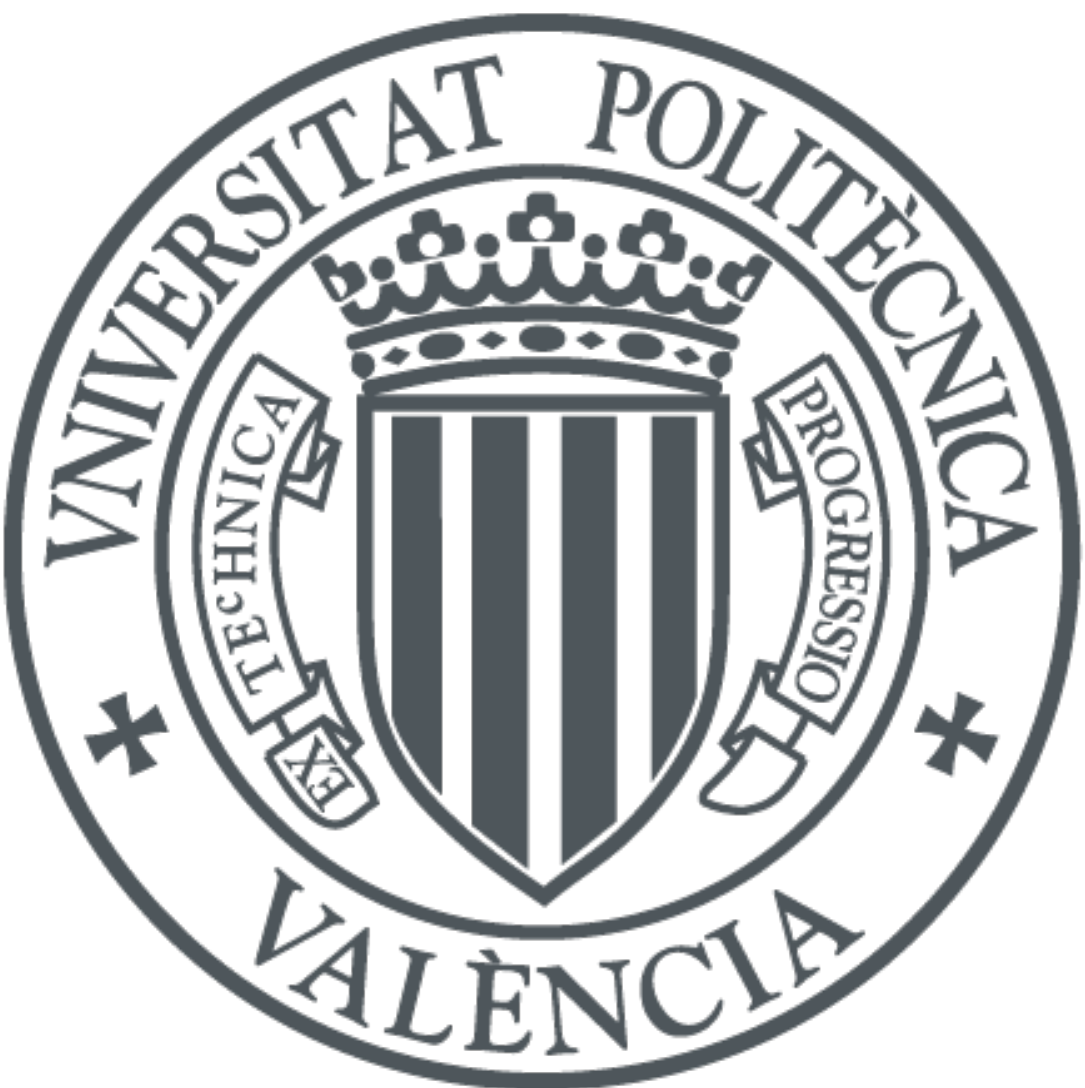

The final publication is available at

http://doi.org/10.1088/0022-3727/48/39/395501

Copyright IOP Publishing

Additional Information 


\title{
SUBWAVELENGTH SLIT ACOUSTIC METAMATERIAL BARRIER
}

\author{
Constanza Rubio, Pilar Candelas, Francisco Belmar, Vicente Gomez-Lozano, Antonio Uris* \\ Centro de Tecnologías Físicas: Acústica, Materiales y Astrofísica. División Acústica. \\ Universitat Politécnica de Valencia. Camino de Vera s/n. 46022 Valencia, Spain. \\ Phone: 34.963877528; Fax: 34.963879525; E-mail: auris@ fis.upv.es \\ *Corresponding author.
}

\begin{abstract}
Reduction of noise in the transmission path is a very important environmental problem. The most usual method to reduce this noise level is the use of acoustic barriers. In this paper, an acoustic metamaterial based on sound transmission through subwavelength slits, is tailored to be used as an acoustic barrier is shown. This system consists of two rows of periodic repetition of vertical rigid pickets separated by a slit of subwavelength width, embedded in air. Here, both the experimental and the numerical analyses are presented. These analyses have facilitated the identification of the parameters that affect the insertion loss performance. The results demonstrated that the proposed barrier can be tuned to mitigate a band noise in mechanical plant for buildings where openings for air flow are required as well as industrial noise, without excessive barrier thickness.
\end{abstract}




\section{INTRODUCTION}

Noise pollution is an important environmental problem in $21^{\text {st }}$ century society, where millions of people around the world are affected by environmental noise. In urban areas where noise pollution is due to different noise sources, such as traffic noise, industrial noise and many other noise sources, the citizens are exposed to high noise levels, which have negative health impacts that are well-known [1,2].

When it is not possible to reduce the emission of the noise acting on the source, it seems appropiate to reduce the noise levels in its transmission, using acoustic barriers [3].

Classical acoustic or noise barriers, defined as solid obstacles placed between a noise source and a receiver, are common devices used to attenuate noise levels during its transmission. The materials used in their construction have to be rigid and with a minimum superficial density of $20 \mathrm{~kg} / \mathrm{m}^{2}$ [4], according to the mass law. With these characteristics, a classical acoustic barrier has a sufficient surface density so that the direct noise transmission through the barrier is blocked. Therefore, the main factor that decreases the effectiveness of a classical acoustic barrier is the diffraction around the top barrier edges. Over the last decades a variety of noise barrier designs have been investigated to increase the screening effect by reducing the effect of diffraction [5].

The development of acoustic metamaterials yielded a new research field in materials science. Acoustic metamaterials are artificial structures that can be engineered to have interesting physical and acoustic properties. Their anomalous physical properties have potential applications to acoustic cloaking [6], to composite materials with negative effective mass density and elastic modulus simultaneously design [7], to noise control applications, etc. Acoustic metamaterials can be created by a periodical arrangement of basic elements. At the end of the nineties, an alternative to these continuous acoustic barriers, based on periodic arrangement of scatterers embedded in air, called sonic crystals, 
as acoustic barriers were proposed [8,9]. Sonic crystals consist of periodic arrays of scatterers that produce high attenuation in selective ranges of frequencies related with their lattice geometry. The mechanism that forbids the transmission of noise, and therefore the noise attenuation, is the destructive Bragg interference due to a multiple scattering process [10]. The advantage of sonic crystal acoustic barriers when compared with conventional ones, apart from the fact that it is frequency tunable, is that the action of wind is relatively small as it is an open structure [11]. Acoustic barriers based on sonic crystals are still a research topic of high interest [12-16], and mainly their study is based on noise transmission due to the fact that they are not continous devices. Nowadays acoustic barriers based on sonic cystals are used to reduce road traffic noise [17]. Locally resonant engineering structures $[18,19]$ are another type of acoustic metamaterial that have been attracting interest. During the last years, ligthweight membrane-type acoustic metamaterials have been proposed as sound insulation materials [20, 21].

In recent years, the so-called extraordinary acoustic transmission through subwavelength apertures has attracted considerable attention to identify the physical mechanisms that contribute to extraordinary acoustic transmission as well as to develop devices for engineering applications. In 2007, Lu et al. [22] reported extraordinary acoustic transmission through a subwavelength slit while acoustic transmission through subwavelength hole arrays was reported experimentally by Hou et al. [23]. Theoretical results for subwavelength slits and holes arrays were reported by Christensen et al. [24]. It is accepted that the phenomena responsible for the acoustic transmission peaks are the Fabry-Perot resonances inside the holes. Estrada et al. [25] showed, both theoretically and experimentally, that water-inmersed perforated plates with periodic subwavelength hole arrays exhibit, at ultrasonic frequencies, higher sound attenuation than predicted by the mass law. Wood anomalies [26] are responsible for this extraordinary shielding. The 
geometrical parameters of the subwavelength hole array also play an important role in acoustic transmission through perforated plates [27, 28]. The ultrasound transmission through two perforated plates with subwavelength hole arrays and separated by an air gap has also been studied [29, 30]. Christensen et al. [31] calculated the transmission coefficient of a single layer slit array metamaterial as a function of frequency and flow speed. They demonstrated that the resonance positions and resonance width changed significantly with flow speed.

The aim of this paper is to present an acoustic metamaterial based on subwavelength slits as an alternative to classical acoustic barriers and to sonic crystal ones. We analyse novel acoustic interferences between propagating and evanescent waves in the air gap region between the slits arrays. The insertion loss peak associated with the acoustic interference varies across the frequency when changing the misalignment between pickets rows. This new acoustic barrier can be tuned as a function of the geometrical parameters in order to mitigate the desired range of frequencies and, as it is an open structure, the action of wind is relatively small and the total thickness is much lower than that of sonic crystal barriers. The proposed barrier can be tuned to mitigate a band noise without excessive barrier thickness. It should be noted that the proposed barrier is a good candidate to be used to reduce noise emissions from the mechanical plants in buildings and in industrial installations where the air flow is necessary. Equipment such as air conditioning units, ventilation and refrigeration systems require openings for air flow. The sound attenuation capabilities of the barrier presented have been analysed both numerically and experimentally.

2. NUMERICAL APPROACH FOR THE ASSESSMENT OF NOISE BARRIER ATTENUATION: FINITE ELEMENT METHOD 
The development of theoretical models that explain the interaction of acoustic waves with different objects, is one of the fundamental pillars of the development of acoustics, allowing us to understand both the underlying physics in new systems and devices, as well as studying their potential technological applications. Due to the geometrical characteristics of the designed structure and the different physical mechanisms involved, the Finite Element Method (FEM) seems a good theoretical tool to design this kind of noise barrier. Using FEM and considering temporal harmonic dependence, the Helmholtz equation given by:

$$
\nabla\left(\frac{1}{\rho} \nabla p\right)=\frac{\omega^{2}}{\rho c^{2}} p
$$

has to be solved, where $\rho$ is the air density, $\mathrm{c}$ is the sound velocity, $\omega$ is the angular frecuency and $\mathrm{p}=\mathrm{p}_{0}+\mathrm{p}_{\mathrm{s}}$ is the acoustic pressure, where $\mathrm{p}_{0}$ corresponds to the incident wave and $\mathrm{p}_{\mathrm{s}}$ to the scattered one.

The main characteristics of the simulations are: i) The pressure acoustics scattered wave module belonging to the commercial software COMSOL 3.5a is used in this work to obtain numerical predictions; ii) Numerical predictions have been obtained by solving eq (1) for the scattered waves, $p_{s}$, at each point of the selected domain because the incident wave, $\mathrm{p}_{0}$, is itself a solution of the wave equation; iii) The model is considered as a 2Dmodel, thereby no diffraction at the top edges can occur and only the transmission attenuation is evaluated; iv) the structure is considered to be acoustically rigid; therefore the Neumann boundary conditions (zero sound velocity) is applied to their surfaces. The structure is formed by one or two rectangles (depending on whether the acoustic barrier has one or two picket rows) with width $\mathrm{w}_{\mathrm{p}}$ and depth $\mathrm{d}_{\mathrm{p}}$, slit width $\mathrm{s}_{\mathrm{w}}$ and the two rows are separated by an air gap $d_{a g}$ and the lateral misalignment between the rows is $m$; $v$ ) these rectangles are confined between two completely reflected walls separated by the lattice 
period, $l_{p}$ and are parallel to the propagation direction of the incident plane wave travelling from left to right. With these conditions, the scattered waves from the rectangles are reflected by the walls reproducing the effect of an infinite acoustic barrier formed by one or two rows of rectangles arranged as shown in Figure 1. At the same time, the incident plane wave is not reflected by the walls. This geometry allows the study of infinite arrays using a reduced volume of the numerical domain, decreasing the computational cost [12]; vi) the consideration of this infinite model has been taken in order to evaluate physical phenomena and allows us to avoid the existence of other unwanted physical effects as diffraction at the end edges; vii) the first and the last boundaries of the domain are surrounded by Perfectly Matched Layers (PML). This method was presented by Berenguer [32] and it is useful to emulate the Sommerfeld condition in the numerical solution of scattering and wave problems.

The consideration of a semi infinite (2D finite) structure involves some differences regarding the model described above. First of all, in this new situation, the numerical domain must be enlarged to include the same number of pickets as used in the experimental configuration. Moreover, the completely reflected walls must be replaced by Perfectly Matched Layers in order to avoid unwanted reflections at the lateral walls.

\section{LABORATORY MEASUREMENTS}

Two basic structures are considered. In the first one, a periodic array of subwavelength slits consisted of rectangular pickets with width $w_{p}$ and depth $d_{p}$, with lattice period $l_{p}$ and slit width $\mathrm{s}_{\mathrm{w}}$, as shown in Figure 2a. The second structure considered has two rows of pickets of width $\mathrm{w}_{\mathrm{p}}$ and depth $\mathrm{d}_{\mathrm{p}}$, distributed periodically with a period $\mathrm{l}_{\mathrm{p}}$ and with a slit width $\mathrm{s}_{\mathrm{w}}$. In both cases, the structure consisted of wood pickets with depth $\mathrm{d}_{\mathrm{p}}=0.1 \mathrm{~m}$, 
width $\mathrm{w}_{\mathrm{p}}=0.30 \mathrm{~m}$ and height $1.8 \mathrm{~m}$. The rows are separated by an air gap $\mathrm{d}_{\mathrm{ag}}$ and the lateral misalignment between the rows is $m$ as shown in Figure $2 b$.

The experiments, under controlled conditions, of the acoustic barrier were carried out in an $8 \times 6 \times 3 \mathrm{~m}^{3}$ anechoic chamber. The measurement system consisted of a bi-dimensional robotized measurement system that locates the prepolarized free-field microphone (Type $4189 \mathrm{~B} \& \mathrm{~K})$ in predefined trajectories in the $\mathrm{XY}$ plane inside the chamber. National Instruments cards were used to synchronise both the microphone and the data acquisition of the temporal signal. Continuous white noise generated by a directional sound source (GENELEC 8040A) located $2 \mathrm{~m}$ from the device was used throughout the measurements in order to consider the wave impinging on the sample as a plane wave. The sample was hanging from a frame in such a way that there is no influence of ground effect. Figure 3 shows a scheme of the experimental device and the measurement system. From the Fast Fourier Transform (FFT) of the temporal signal, the sound level as a function of frequency was obtained. The frequency range $100-3000 \mathrm{~Hz}$ was covered in $6 \mathrm{~Hz}$ steps in order to detect sharp peaks and dips resulting from interference phenomena that, by using $1 / 3$ octave band center frequency, could not be observed. The acoustic attenuation properties of this barrier are represented by its attenuation spectrum in the chosen range of frequencies (100-3000 Hz), characterised by means of the insertion loss (IL), defined as the difference between the sound pressure levels recorded at the same point with (interfered pressure field) and without (direct pressure field) the barrier

$$
\mathrm{IL}=20 \cdot \log _{10}\left|\frac{\mathrm{p}_{\text {Direct }}}{\mathrm{p}_{\text {Interfered }}}\right|
$$

Therefore, the insertion loss of a transversal section of the sample has been calculated as an index to evaluate the attenuation properties of the proposed subwavelength acoustic barrier. 
By means of the robotised measurement system, an area of $1 \mathrm{~m}^{2}$ in the XY plane was measured to verify that differences in $\mathrm{IL}$ are less than $1 \mathrm{~dB}$ for all frequencies above 250 Hz. Under this conditions, the nearest point to the sample was located $1.5 \mathrm{~m}$ away from it and therefore as the differences were less than $1 \mathrm{~dB}$, it was sufficient to choose a single point within this area, located $2.2 \mathrm{~m}$ from the sample and $1.2 \mathrm{~m}$ high, to assess the IL.

\section{RESULTS AND DISCUSSION}

In order to assess the accuracy of the calculation model, the calculated and measured results are compared for a single row of periodic array of pickets of depth $d_{p}=0.1 \mathrm{~m}$, slit width $\mathrm{s}_{\mathrm{w}}=0.05 \mathrm{~m}$ and picket width $\mathrm{w}_{\mathrm{p}}=0.30$. Fig. 4 shows the comparison between measured and calculated insertion loss at normal incidence. The qualitative nature of experimental results is consistent with numerical results. As the height of the pickets is considered infinite, the diffraction at the top edge is not considered. In the 2D finite model, only the transmission through the barrier and the diffraction around the lateral edges are considered.

The sound transmission properties of a single row of periodic array of subwavelength slits can be explored by calculating the insertion loss, IL, as a function of the frequency $\mathrm{f}$. A typical transmission spectrum is obtained when a sound wave impinges at normal incidence onto a periodic array of subwavelength slits. Figure 5 shows calculated insertion loss at normal incidence for a 2D infinite periodic array of pickets of depth $d_{p}=0.1 \mathrm{~m}$ and a slit width of $s_{w}=0.05 \mathrm{~m}$. Three different values of picket width $\mathrm{w}_{\mathrm{p}}=0.15,0.25$ and 0.30 $\mathrm{m}$ and, therefore, three different lattice periods $1_{p}=0.20,0.30$ and $0.35 \mathrm{~m}$ have been considered. It has been observed that the insertion loss spectra follow a typical acoustic filter pattern. Pronounced insertion loss peaks that are the exact manifestation of the Wood anomaly similar to those observed in optical gratings [26] have been clearly seen. Wood 
anomalies are observed when light impinges in optical diffraction gratings. Rapid variations in the intensity of specific diffracted spectral orders in narrow frequency bands were observed. The Wood anomaly for normal incidence in a periodic array of subwavelength slits is given by $\lambda=l_{p}$, where $\lambda$ is the wavelength and $l_{\mathrm{p}}$ is the lattice period. The positions of the Wood anomalies are $1700 \mathrm{~Hz}$ for the periodic array with $\mathrm{l}_{\mathrm{p}}$ $=0.20 \mathrm{~m}, 1133 \mathrm{~Hz}$ and $2266 \mathrm{~Hz}$ for the periodic array with $\mathrm{l}_{\mathrm{p}}=0.30 \mathrm{~m}$ and $971 \mathrm{~Hz}$ and $1942 \mathrm{~Hz}$ for the periodic array with $\mathrm{l}_{\mathrm{p}}=0.35 \mathrm{~m}$. The Wood anomaly at the frequency $1942 \mathrm{~Hz}$ is not clearly observed due to the interference with the Fabry-Perot resonance. Another effect observed in the insertion loss of a periodic array of subwavelength slits is the Fabry-Perot resonance. From the open tube, the Fabry-Perot resonant condition is $f_{F P}=n \frac{c}{2 d_{p}}$, where $\mathrm{c}$ is the speed of sound in air and $\mathrm{n}=1,2,3, \ldots$ It is seen that there are resonant insertion loss dips that are directly related to the picket depth, therefore, when the picket depth increases, more insertion loss dips will appear and they will move towards lower frequencies. Figure 6 shows calculated insertion loss at normal incidence for a $2 \mathrm{D}$ infinite periodic array of pickets with a slit width $\mathrm{s}_{\mathrm{w}}=0.05 \mathrm{~m}$, a picket width $\mathrm{w}_{\mathrm{p}}=$ $0.25 \mathrm{~m}$ and three different values of picket depth $\mathrm{d}_{\mathrm{p}}=0.10,0.15$ and $0.20 \mathrm{~m}$.

As the intention is to increase the insertion loss of the structure, so that it can be used as an acoustic barrier, a second row of pickets is added to the first row. The effect on the insertion loss of the air gap between the picket rows is considered first. The acoustic barrier considered has two rows of pickets of depth $d_{p}=0.1 \mathrm{~m}$ and width $\mathrm{w}_{\mathrm{p}}=0.30 \mathrm{~m}$, slit width $\mathrm{s}_{\mathrm{w}}=0.05 \mathrm{~m}$ and a lattice period $1_{\mathrm{p}}=0.35 \mathrm{~m}$. The lateral misalignment between the rows was $\mathrm{m}=0.175 \mathrm{~m}$ and three different values of air gaps between rows were considered, $\mathrm{d}_{\mathrm{ag}}=0.05,0.07$ and $0.10 \mathrm{~m}$. Figure 7 shows calculated insertion loss at normal 
incidence for the acoustic barrier obtained by using the 2D infinite numerical model. In this case, the acoustic barrier can be considered as a series of expansion chambers, with an inlet aperture in the first picket row, the air gap between picket rows acts as an expansion chamber and outlet aperture in the second picket row. Moreover, the effect of the expansion chamber, the manifestation of the Wood anomaly at a frequency of $971 \mathrm{~Hz}$ is clearly seen. It is also observed that, as could be expected, the insertion loss increases as the air gap between rows increases. In the case of the acoustic barrier with an air gap between rows $d_{\mathrm{ag}}=0.10 \mathrm{~m}$, a sharp insertion loss peak at a frequency of around $1500 \mathrm{~Hz}$ is observed. This frequency corresponds to destructive interference between the odd and even Fabry-Perot modes [33], resulting in an insertion loss increase. The insertion loss of the acoustic barrier has been measured experimentally in the anechoic chamber. Each row consisted of six pickets separated by a slit of width $\mathrm{s}_{\mathrm{w}}=0.05 \mathrm{~m}$. The lateral misalignment between the rows was $\mathrm{m}=0.175 \mathrm{~m}$. Three air gaps between rows were considered, $\mathrm{d}_{\mathrm{ag}}=$ $0.05,0.07$ and $0.10 \mathrm{~m}$. Calculated results by using the $2 \mathrm{D}$ finite model are shown in Figure $8 \mathrm{a}$, and measured results are shown in Figure $8 \mathrm{~b}$. In measured results we observed the fundamental features of calculated results. The insertion loss peaks corresponding to the Wood anomaly and to the destructive interference between the odd and even Fabry-Perot modes are clearly observed. The insertion loss peak at a frequency of around $600 \mathrm{~Hz}$ is explained as a destructive interference between the propagating and evanescent waves [34]. The discrepancies between calculated and measured results are probably due to the fact that the height of the pickets in the calculated barrier is considered infinite, thus no diffraction at the top edge is taken into account, so only the transmission through the barrier and the diffraction around the lateral edges are evaluated. On the other hand, viscous losses are not included in the calculations. 
Another parameter that could influence in the insertion loss of the acoustic barrier is the misalignment between the rows. Figure 9 shows calculated insertion loss at normal incidence for the acoustic barrier obtained by using the 2D infinite numerical model, with pickets of depth $d_{p}=0.1 \mathrm{~m}$ and width $\mathrm{w}_{\mathrm{p}}=0.30 \mathrm{~m}$, slit width $\mathrm{s}_{\mathrm{w}}=0.05 \mathrm{~m}$, lattice period $\mathrm{l}_{\mathrm{p}}$ $=0.35 \mathrm{~m}$ and air gap between rows $\mathrm{d}_{\mathrm{ag}}=0.10 \mathrm{~m}$. Four different values of lateral misalignment between the rows were considered $\mathrm{m}=0,0.05,0.10$ and $0.175 \mathrm{~m}$. It is observed that, as the lateral misalignment is reduced, insertion loss peaks appear at fequencies between 500 and $800 \mathrm{~Hz}$ which, in the case of lateral misalignment $\mathrm{m}=0.175$, did not appear. As mentioned above, these peaks are due to a destructive interference between the propagating and evanescent waves. The insertion loss peaks corresponding to the Wood anomaly and the destructive interference between the odd and even FabryPerot modes remain invariable. Calculated results by using 2D finite model and measured ones are shown in Figure 10a and 10b respectively. Measured results are consistent with calculated ones and fundamental features of the calculated results are observed.

\section{CONCLUSIONS}

This paper presents an acoustic metamaterial based on acoustic transmission through subwavelength slits to be used as an acoustic barrier. This one was built with two rows of vertical pickets which were periodically distributed The idea behind this design is to obtain an open acoustic barrier that could be tuned to suppress a band noise without an excessive thickness. Due to the separation between the pickets, the air can flow through the barrier, so that it could also be used in industrial installations where the airflow is necessary. The role of the geometrical parameters on the insertion loss of the barrier has been analysed. The mechanisms that explain the noise attenuation in certain frequency ranges are the Wood anomalies and the destructive interference between the odd and 
even Fabry-Perot modes. Both phenomena depend on the geometrical parameters of the barrier such as periodicity, pickets depth and air gaps between picket rows. Laboratory measurements in the anechoic chamber have been carried out in order to compare the results with FEM calculations. The qualitative nature and the fundamental features of the experimental results are consistent with the numerical results. The discrepancies between the calculated by using the 2D finite numerical model and measured results are due the fact that, in the simulated barriers, viscous losses are not included and no diffraction at the top edge is taken into account, so only the transmission through the barrier and the diffraction around the lateral edges are evaluated. The proposed barrier can be used in many buildings where the mechanical plant requires openings for air flow as an alternative to acoustic louvers which do not attenuate all noise passing through them.

\section{Acknowledgements}

This work was financially supported by the Spanish Ministry of Science and Innovation through project MAT2010-16879.

\section{REFERENCES}

[1] Commission of the European Communities 1996 Green Paper on "Future Noise Policy” COM(96)540 Brussels.

[2] WHO 2011. Burden of disease from environmental noise: quantification of healthy life years lost in Europe WHO Regional Office for Europe.

[3] Harris, CM 1991 Handbook of acoustical measurements and noise control 3rd ed. Mc Graw-Hill. 
[4] Department of Transportation, Federal Highway Administration U.S.A. 2001 Keeping the Noise Down. Highway Traffic Noise Barriers Washington FHWA-EP-01-004 HEPN/2-01 $(10 \mathrm{M}) \mathrm{E}$.

[5] Ekici I, Bougdah H 2003 Building Acoustics 10 289-323.

[6] Shen H, Païdoussis MP, Wen J, Yu D, Cai L, Wen X 2012 J. Phys. D: Appl. Phys. 45 285401

[7] Jin Y, Bonello B, Pan Y 2014 J. Phys. D: Appl. Phys. 47245301

[8] Sánchez-Perez JV, Caballero D, Martinez-Sala R, Sánchez-Dehesa J, Rubio C, Meseguer F, Llinares J, Gálvez F 1998 Phys. Rev. Lett. 805325.

[9] Sánchez-Pérez JV, Rubio C, Martinez-Sala R, Sánchez-Grandia R, Gomez V 2002 Appl. Phys. Lett. 815240.

[10] Chen YY, Ye Z 2001 Phys. Rev. E. 64036616

[11] Castiñeira-Ibáñez S, Rubio C, Romero-García V, Sánchez-Pérez JV, L.M. García-Raffi LM 2012 Arch. Acoustic. 37 455-462.

[12] Castiñeira-Ibañez S, Rubio C, Sanchez-Perez JV 2013 EPL 10164002

[13] Umnova O, Attenborough K, Linton CM 2006 J. Acoust. Soc. Am. 119 278-284.

[14] Romero-Garcia V, Sánchez-Pérez JV, Garcia-Raffi, LM 2011 J. Appl. Phys. 110 014904.

[15] Koussa F, Defrance J, Jean P, Blac-Benon P 2013 Acta Acustica united with Acustica 99 $399-409$.

[16] Van der Aa B, Forssén J 2014 Appl. Acoust. 78 98-111.

[17] Van Kemenade RC 2010 The Sound of Silence. Aluminium Noise-reducing Devices, a revolutionary high-tech Solution along the A2 near Eindhoven (Holland). 11th International Aluminium Conference - 'INALCO' 2010 'New Frontiers in Light Metals' Laurens Katgerman and Frans Soetens (Eds.) IOS Press 213-222. 
[18] Hsu JC 2011 J. Phys. D: Appl. Phys. 44055401

[19] Xiao Y, Wen J, Wen X 2012 J. Phys. D: Appl. Phys. 45195401

[20] Yang Z, Dai HM, Chan NH, Ma GC, Sheng P 2010 Appl. Phys. Lett. 96041906

[21] Ma F, Wu JH, Huang M, Zhang W, Zhang S 2015 J. Phys. D: Appl. Phys. 48175105

[22] Lu M.H, Liu XK, Feng L, Li J, Huang CP, Chen YF, Zhu YY, Zhu SN, Ming NB 2007 Phys. Rev. Lett. 99174301.

[23] Hou B, Mei J, Ke M, Wen W, Liu Z, Shi J, Sheng P 2007 Phys. Rev. B 76 054303.

[24] Christensen J, Martin-Moreno L, Garcia-Vidal FJ 2008 Phys. Rev. Lett. 101014301.

[25] Estrada H, Candelas P, Uris A, Belmar F, García de Abajo FJ, Meseguer F 2008 Phys. Rev. Lett. 101084302.

[26] Wood RW 1935 Phys. Rev. 48(12): 928-936.

[27] Estrada H, Candelas P, Uris A, Belmar F, Meseguer F, García de Abajo FJ 2008 Appl. Phys. Lett. 93011907.

[28] Estrada H, Candelas P, Uris A, Belmar F, García de Abajo FJ, Meseguer F 2009 Appl. Phys. Lett. 95051906.

[29] Bell JS, Summers IR, Murray ARJ, Hendry E, Sambles JR, Hibbins AP 2012 Phys. Rev. B 85214305 .

[30] Murray ARJ, Hendry E, Summers IR, Sambles JR, Hibbins AP 2013 J. Acoust. Soc. Am. 134 1754-1759.

[31] Christensen J, Willatzen M 2012 Phys. Rev. B 85094304

[32] Berenguer JP 1994 J Comput. Phys. 114 185-200.

[33] Liu Z, Jin G. 2010 J. Phys.: Condens. Matter. 22305003.

[34] Akiyama K, Takano K, Abe Y, Tokuda Y, Hangyo M. 2010 Optic Express 181787617882. 


\section{FIGURES CAPTIONS}

Figure 1. Schematic diagram of the configuration simulated in the numerical domain where the solutions are obtained

Figure 2. Schematic diagram of the acoustic barrier consisting of (a) a single picket row (b) two picket rows, where $\mathrm{w}_{\mathrm{p}}$ is the picket width, $\mathrm{s}_{\mathrm{w}}$ the slit width and $\mathrm{l}_{\mathrm{p}}$ the lattice period. For the two picket rows the misalignment $(\mathrm{m})$ and the air gap $\left(\mathrm{d}_{\mathrm{ag}}\right)$ between the two rows have also been considered.

Figure 3. Scheme of the anechoic chamber with the experimental device and the measurement system

Figure 4. Measured and numerically calculated insertion loss at normal incidence by using the 2D infinite and 2D finite numerical model for a single row of periodic array of pickets of depth $\mathrm{d}_{\mathrm{p}}=0.1 \mathrm{~m}$, slit width $\mathrm{s}_{\mathrm{w}}=0.05 \mathrm{~m}$ and picket width $\mathrm{w}_{\mathrm{p}}=0.30$.

Figure 5. Calculated insertion loss at normal incidence by using the 2D infinite numerical model for a periodic array of pickets of depth $d_{p}=0.1 \mathrm{~m}$, slit width $\mathrm{s}_{\mathrm{w}}=0.05 \mathrm{~m}$ and three different values of picket width, $\mathrm{w}_{\mathrm{p}}=0.15,0.25$ and 0.30 .

Figure 6. Calculated insertion loss at normal incidence by using the 2D infinite numerical model for a periodic array of pickets with a slit width $\mathrm{s}_{\mathrm{w}}=0.05 \mathrm{~m}$, a picket width $\mathrm{w}_{\mathrm{p}}=0.25 \mathrm{~m}$ and three different values of picket depth $d_{p}=0.10,0.15$ and $0.20 \mathrm{~m}$. 
Figure 7. Calculated insertion loss at normal incidence by using the $2 \mathrm{D}$ infinite numerical model for an acoustic barrier with two rows of pickets of depth $d_{p}=0.1 \mathrm{~m}$ and width, $\mathrm{w}_{\mathrm{p}}=0.30 \mathrm{~m}$, slit width $\mathrm{s}_{\mathrm{w}}=0.05 \mathrm{~m}$, a lattice period $\mathrm{l}_{\mathrm{p}}=0.35 \mathrm{~m}$ and the lateral misalignment between the rows is $\mathrm{m}=0.175 \mathrm{~m}$. Three different values of air gaps between rows are considered, $\mathrm{d}_{\mathrm{ag}}=0.05,0.07$ and $0.10 \mathrm{~m}$.

Figure 8. (a) Calculated insertion loss at normal incidence obtained by using the 2D finite numerical model and (b) measured insertion loss for an acoustic barrier with two rows of pickets of depth $d_{p}=0.1 \mathrm{~m}$ and width, $\mathrm{w}_{\mathrm{p}}=0.30 \mathrm{~m}$, slit width $\mathrm{s}_{\mathrm{w}}=0.05 \mathrm{~m}$, a lattice period $\mathrm{l}_{\mathrm{p}}=0.35 \mathrm{~m}$ and the lateral misalignment between the rows is $\mathrm{m}=0.175 \mathrm{~m}$. Three different values of air gap between rows are considered, $d_{\mathrm{ag}}=0.05,0.07$ and $0.10 \mathrm{~m}$.

Figure 9. Calculated insertion loss at normal incidence obtained by using the $2 \mathrm{D}$ infinite numerical model for an acoustic barrier with two rows of pickets of depth $d_{p}=0.1 \mathrm{~m}$ and width, $\mathrm{w}_{\mathrm{p}}=0.30 \mathrm{~m}$, slit width $\mathrm{s}_{\mathrm{w}}=0.05 \mathrm{~m}$, a lattice period $\mathrm{l}_{\mathrm{p}}=0.35 \mathrm{~m}$ and an air gap between rows $\mathrm{d}_{\mathrm{ag}}$ $=0.10 \mathrm{~m}$. Four different values of the lateral misalignment between the rows are considered $\mathrm{m}$ $=0,0.05,0.10$ and $0.175 \mathrm{~m}$.

Figure 10. (a) Calculated insertion loss at normal incidence obtained by using the 2D finite numerical model and (b) measured insertion loss for an acoustic barrier with two rows of pickets of depth $d_{p}=0.1 \mathrm{~m}$ and width, $\mathrm{w}_{\mathrm{p}}=0.30 \mathrm{~m}$, slit width $\mathrm{s}_{\mathrm{w}}=0.05 \mathrm{~m}$, a lattice period $\mathrm{l}_{\mathrm{p}}=0.35 \mathrm{~m}$ and an air gap between rows $d_{a g}=0.10 \mathrm{~m}$. Four different values of the lateral misalignment between the rows are considered $\mathrm{m}=0,0.05,0.10$ and $0.175 \mathrm{~m}$. 


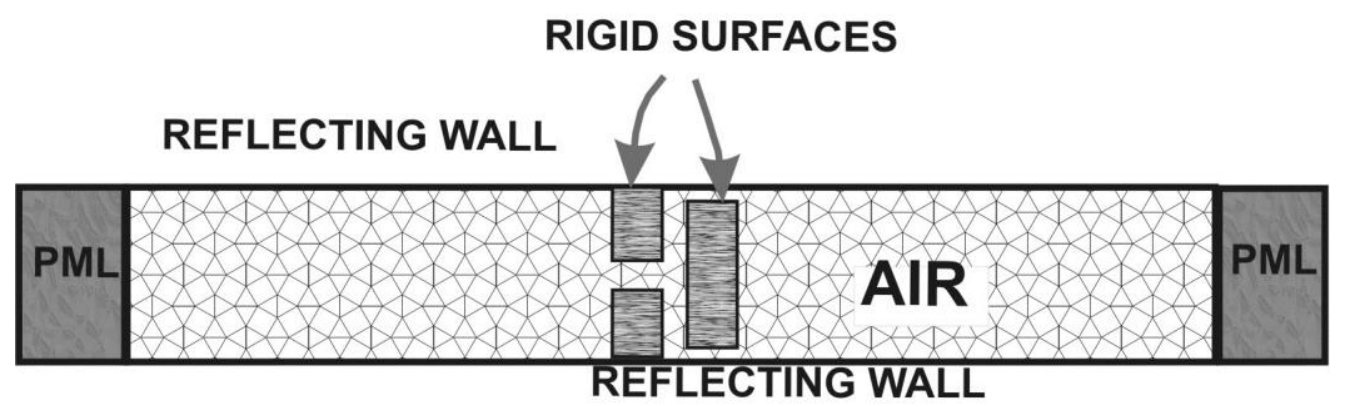

Figure 1. Schematic diagram of the configuration simulated in the numerical domain where the solutions are obtained 


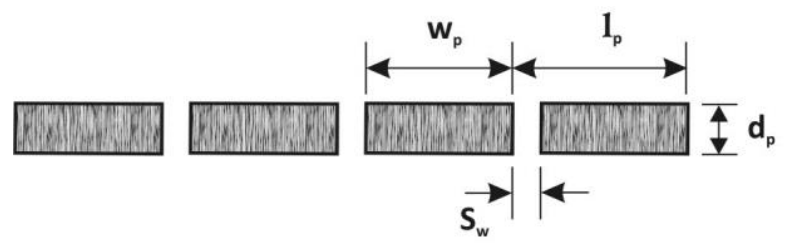

Figure $2 \mathrm{a}$

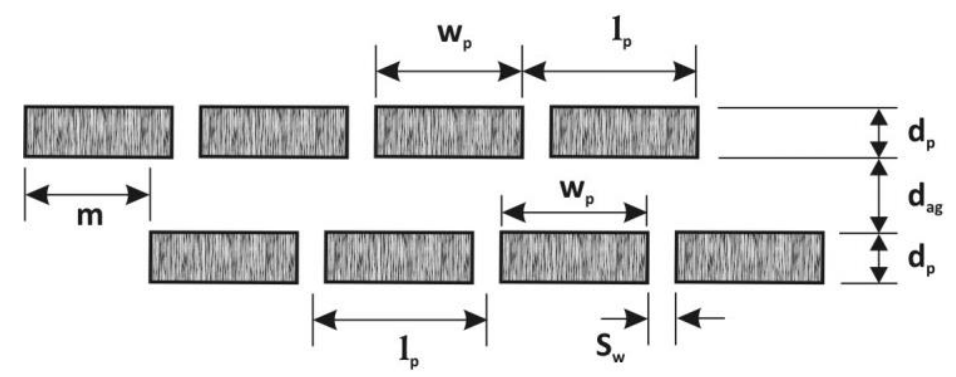

Figure $2 b$

Figure 2. Schematic diagram of the acoustic barrier consisting of (a) a single picket row (b) two picket rows, where $\mathrm{w}_{\mathrm{p}}$ is the picket width, $\mathrm{s}_{\mathrm{w}}$ the slit width and $\mathrm{l}_{\mathrm{p}}$ the lattice period. For the two picket rows the misalignment $(\mathrm{m})$ and the air gap $\left(\mathrm{d}_{\mathrm{ag}}\right)$ between the two rows have also been considered. 


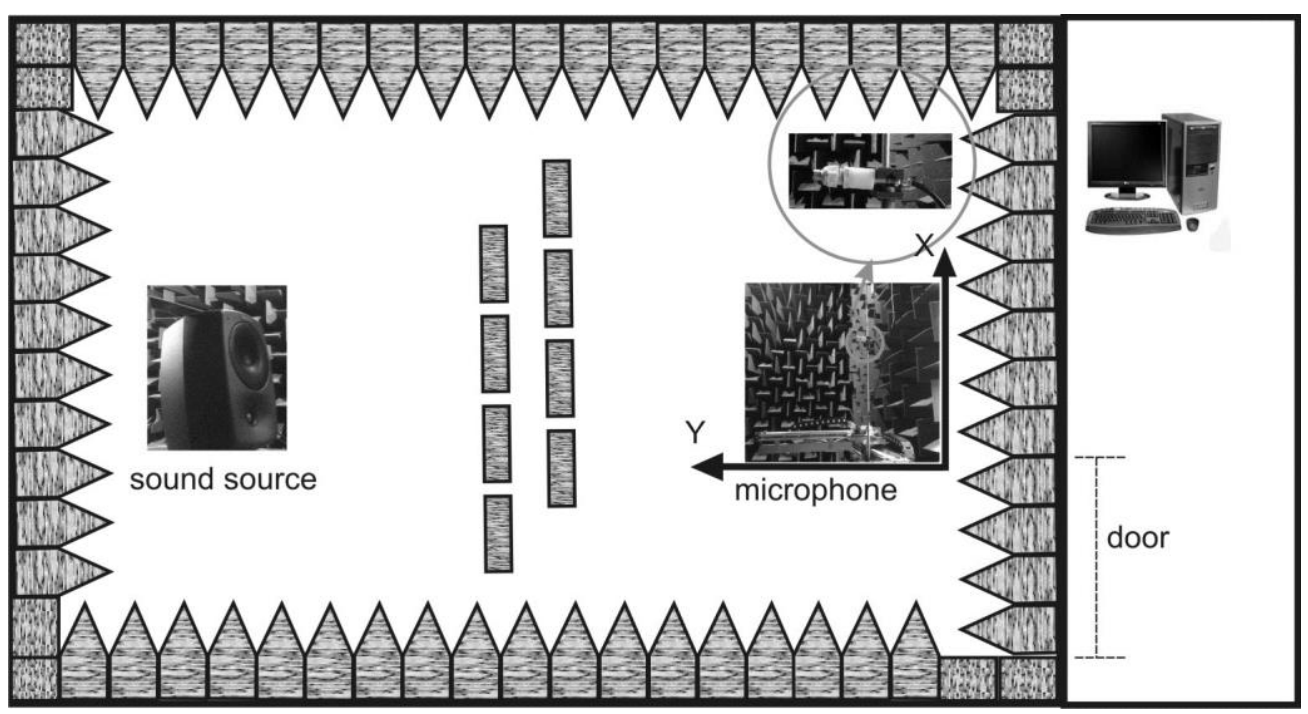

Figure 3. Scheme of the anechoic chamber with the experimental device and the measurement system 


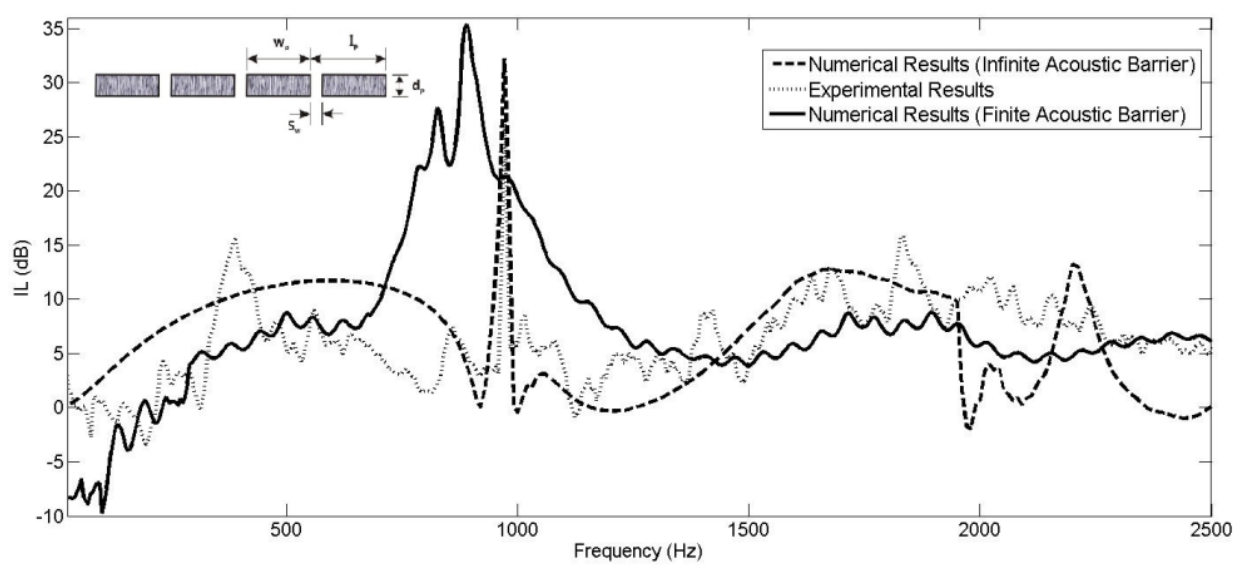

Figure 4. Measured and numerically calculated insertion loss at normal incidence by using the 2D infinite and 2D finite numerical model for a single row of periodic array of pickets of depth $\mathrm{d}_{\mathrm{p}}=0.1 \mathrm{~m}$, slit width $\mathrm{s}_{\mathrm{w}}=0.05 \mathrm{~m}$ and picket width $\mathrm{w}_{\mathrm{p}}=0.30$. 


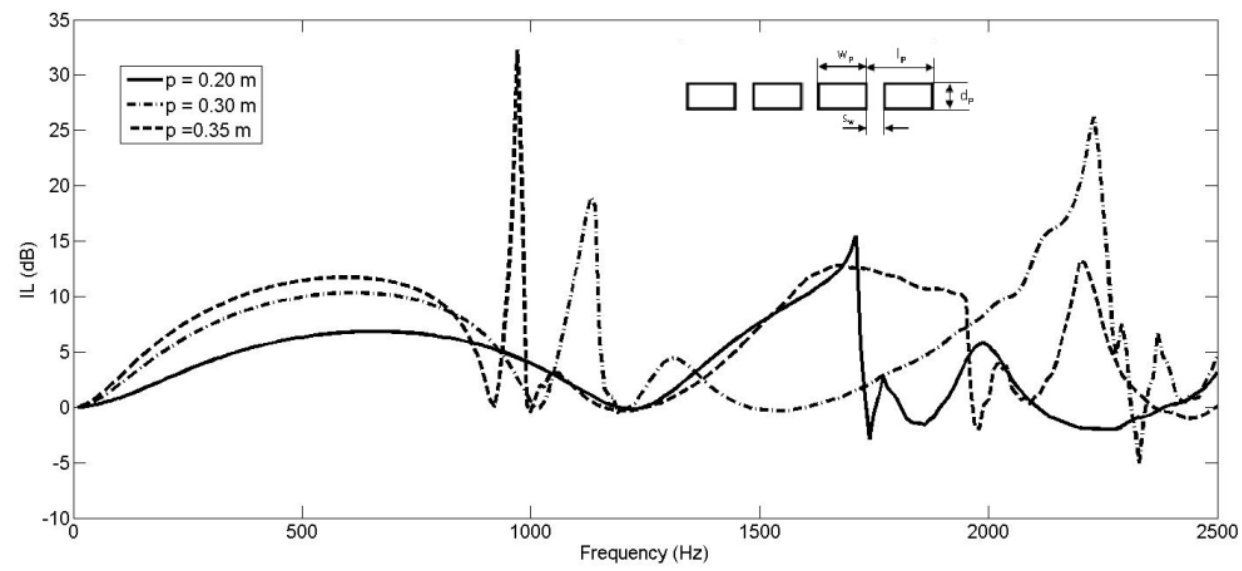

Figure 5. Calculated insertion loss at normal incidence by using the 2D infinite numerical model for a periodic array of pickets of depth $d_{p}=0.1 \mathrm{~m}$, slit width $\mathrm{s}_{\mathrm{w}}=0.05 \mathrm{~m}$ and three different values of picket width, $\mathrm{w}_{\mathrm{p}}=0.15,0.25$ and 0.30 . 


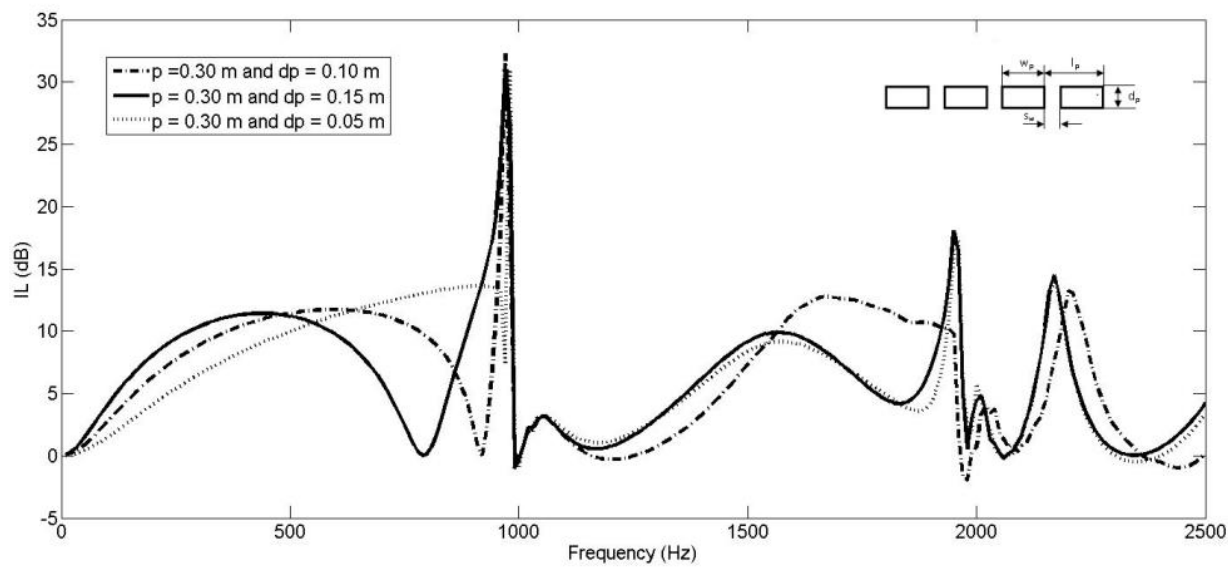

Figure 6. Calculated insertion loss at normal incidence by using the $2 \mathrm{D}$ infinite numerical model for a periodic array of pickets with a slit width $\mathrm{s}_{\mathrm{w}}=0.05 \mathrm{~m}$, a picket width $\mathrm{w}_{\mathrm{p}}=0.25 \mathrm{~m}$ and three different values of picket depth $d_{p}=0.10,0.15$ and $0.20 \mathrm{~m}$. 


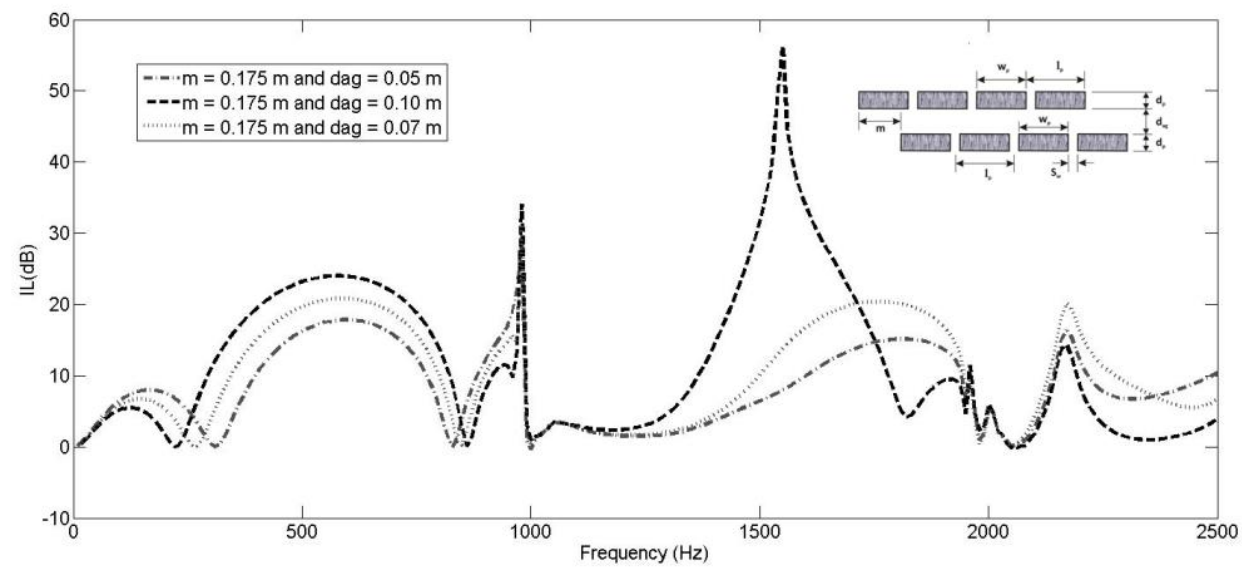

Figure 7. Calculated insertion loss at normal incidence by using the 2D infinite numerical model for an acoustic barrier with two rows of pickets of depth $d_{p}=0.1 \mathrm{~m}$ and width, $\mathrm{w}_{\mathrm{p}}=0.30 \mathrm{~m}$, slit width $\mathrm{s}_{\mathrm{w}}=0.05 \mathrm{~m}$, a lattice period $\mathrm{l}_{\mathrm{p}}=0.35 \mathrm{~m}$ and the lateral misalignment between the rows is $\mathrm{m}=0.175 \mathrm{~m}$. Three different values of air gaps between rows are considered, $\mathrm{d}_{\mathrm{ag}}=0.05,0.07$ and $0.10 \mathrm{~m}$. 


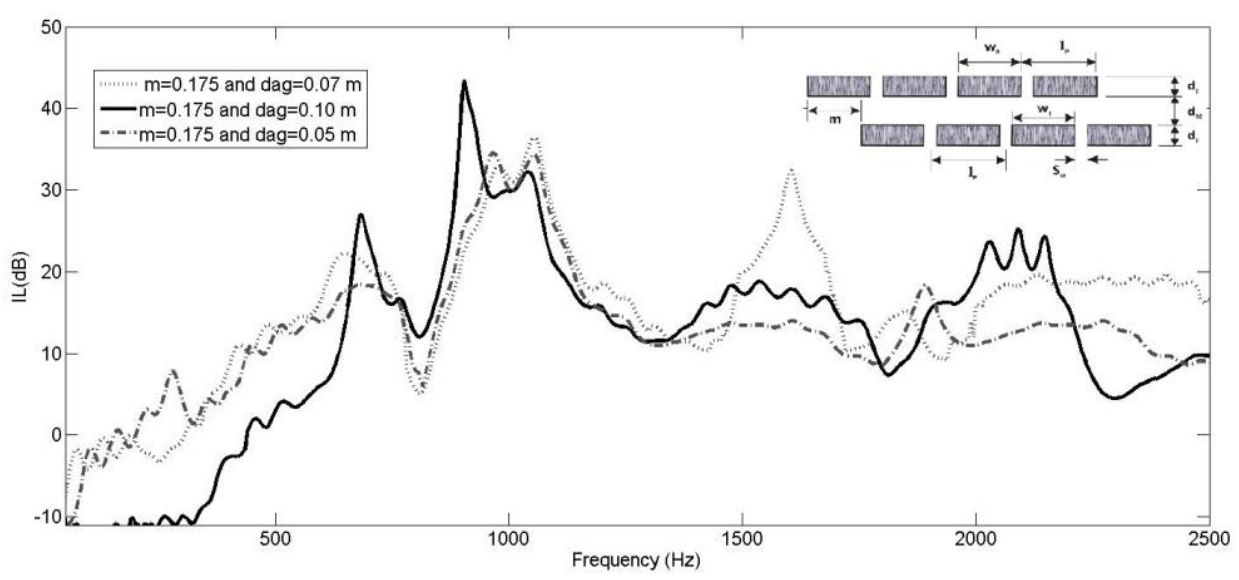

Figure 8a

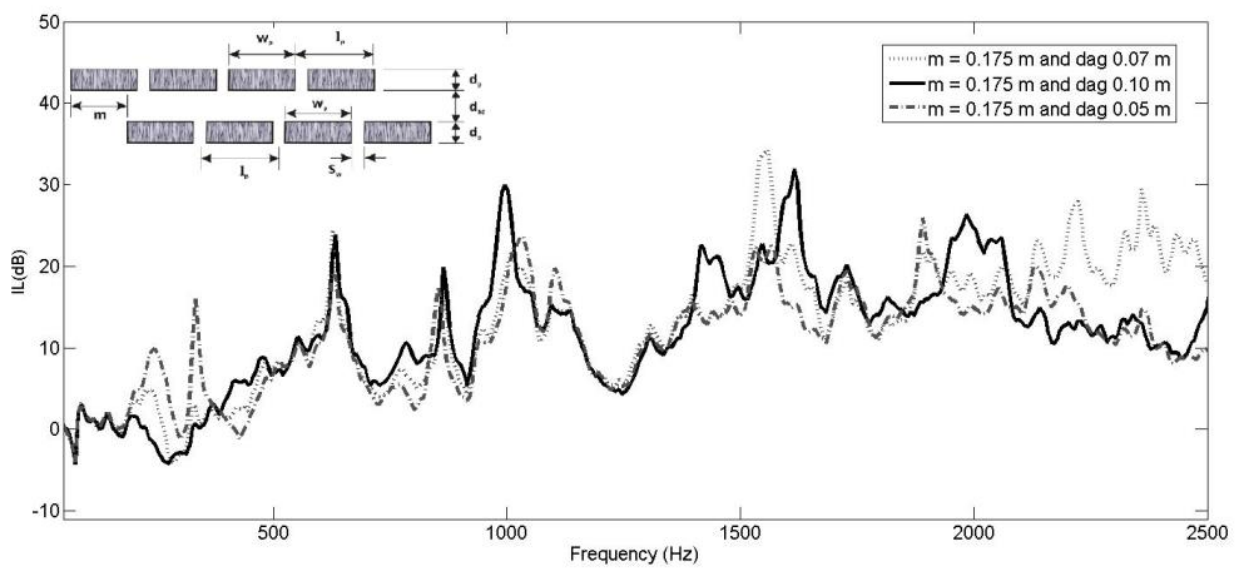

Figure $8 b$

Figure 8. (a) Calculated insertion loss at normal incidence obtained by using the 2D finite numerical model and (b) measured insertion loss for an acoustic barrier with two rows of pickets of depth $d_{p}=0.1 \mathrm{~m}$ and width, $\mathrm{w}_{\mathrm{p}}=0.30 \mathrm{~m}$, slit width $\mathrm{s}_{\mathrm{w}}=0.05 \mathrm{~m}$, a lattice period $\mathrm{l}_{\mathrm{p}}=0.35 \mathrm{~m}$ and the lateral misalignment between the rows is $\mathrm{m}=0.175 \mathrm{~m}$. Three different values of air gap between rows are considered, $d_{\mathrm{ag}}=0.05,0.07$ and $0.10 \mathrm{~m}$. 


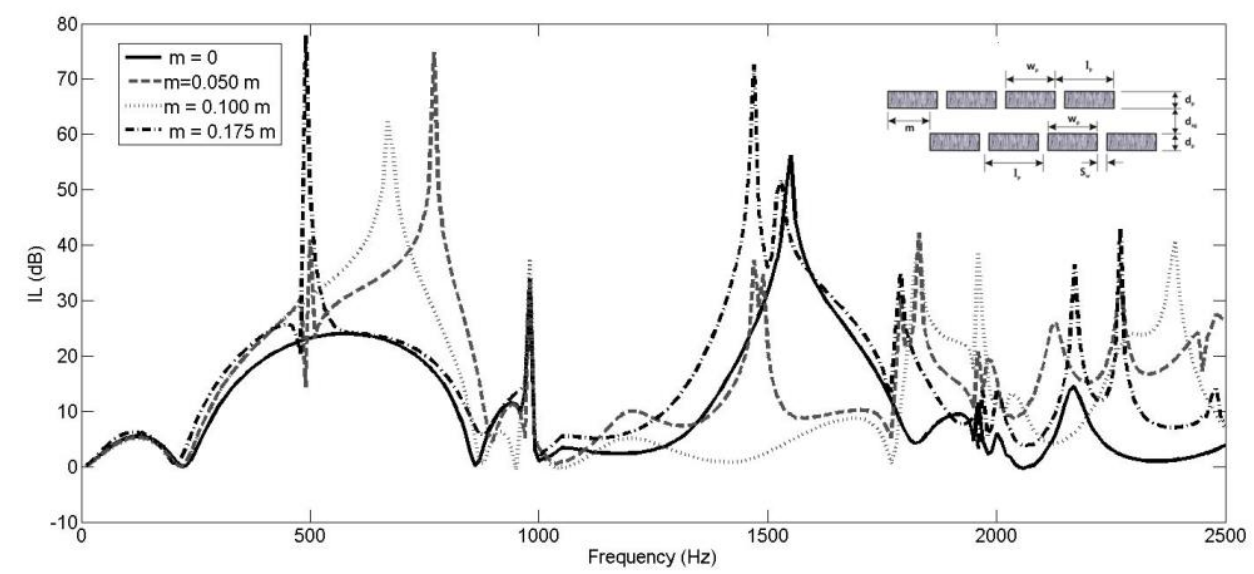

Figure 9. Calculated insertion loss at normal incidence obtained by using the $2 \mathrm{D}$ infinite numerical model for an acoustic barrier with two rows of pickets of depth $d_{p}=0.1 \mathrm{~m}$ and width, $\mathrm{w}_{\mathrm{p}}=0.30 \mathrm{~m}$, slit width $\mathrm{s}_{\mathrm{w}}=0.05 \mathrm{~m}$, a lattice period $\mathrm{l}_{\mathrm{p}}=0.35 \mathrm{~m}$ and an air gap between rows $\mathrm{d}_{\mathrm{ag}}$ $=0.10 \mathrm{~m}$. Four different values of the lateral misalignment between the rows are considered $\mathrm{m}$ $=0,0.05,0.10$ and $0.175 \mathrm{~m}$. 


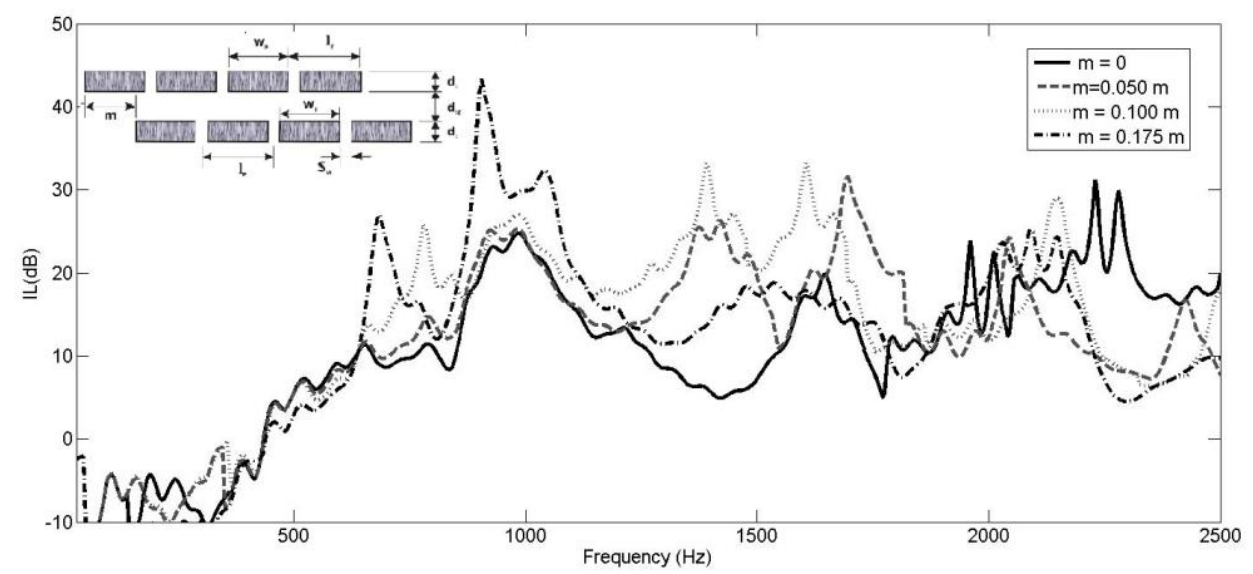

Figure 10a

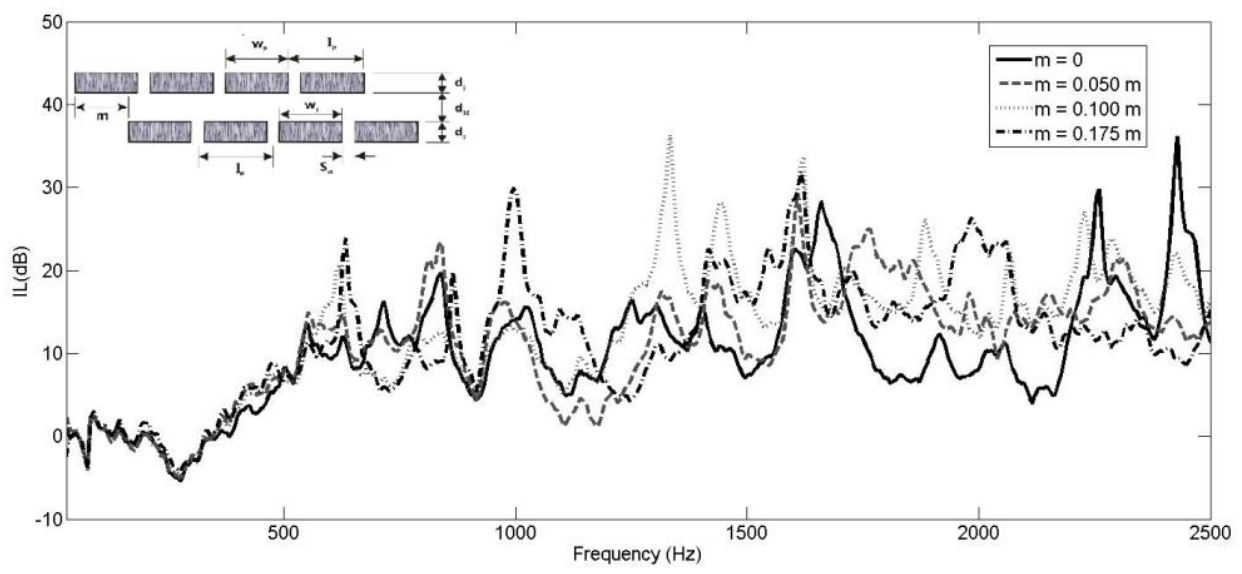

Figure 10b

Figure 10. (a) Calculated insertion loss at normal incidence obtained by using the 2D finite numerical model and (b) measured insertion loss for an acoustic barrier with two rows of pickets of depth $d_{p}=0.1 \mathrm{~m}$ and width, $\mathrm{w}_{\mathrm{p}}=0.30 \mathrm{~m}$, slit width $\mathrm{s}_{\mathrm{w}}=0.05 \mathrm{~m}$, a lattice period $\mathrm{l}_{\mathrm{p}}=0.35 \mathrm{~m}$ and an air gap between rows $d_{a g}=0.10 \mathrm{~m}$. Four different values of the lateral misalignment between the rows are considered $\mathrm{m}=0,0.05,0.10$ and $0.175 \mathrm{~m}$. 